\title{
Natural radioelement concentrations in the soil of the Mila region of Algeria
}

\author{
Amina BRAMKI ${ }^{1}$, Mourad RAMDHANE $^{2}$, Fatima $^{\text {BENRACHI }}{ }^{1}$
}

${ }^{1}$ Mathematics and Subatomic Physics Laboratory (LMPS), University of Constantine-1, Constantine 25017, Algeria

${ }^{2}$ LPSC, Université Grenoble Alpes, CNRS/IN2P3, Institut National Polytechnique de Grenoble, F-38026 Grenoble Cedex, France

\begin{abstract}
In this study, the levels of the natural and artificial radioactivity in soil samples collected at various depths from Algerian agricultural region El-Athmania Mila was measured. Activity concentrations of the concerned radionuclides were determined by gamma-ray spectrometry using a high-purity germanium detector. The activity concentrations of ${ }^{226} \mathrm{Ra},{ }^{232} \mathrm{Th}$ and ${ }^{40} \mathrm{~K}$ were found unchanged as a function of depth and ranged from $23.72 \pm 2.37$ to $65.47 \pm 5.06 \mathrm{~Bq} \cdot \mathrm{kg}^{-1}$ for ${ }^{226} \mathrm{Ra}$, from $26.45 \pm 0.78$ to $27.10 \pm 0.80 \mathrm{~Bq} \cdot \mathrm{kg}^{-1}$ for ${ }^{232} \mathrm{Th}$ and from $220.80 \pm 10.01$ to $260.70 \pm 8.24 \mathrm{~Bq} \cdot \mathrm{kg}^{-1}$ for ${ }^{40} \mathrm{~K}$ respectively. To evaluate the radiological hazard of radioactivity in samples, the radium equivalent activity (Raeq), the absorbed dose rate (D), the annual effective dose and the external (Hex) and internal hazard indices (Hin) were calculated. The mean of the excess lifetime cancer risk observed in this study are under the world's mean values.
\end{abstract}

\section{Introduction}

Every day, we ingest and inhale radionuclides via the consumption of food, water and air. All types of food including wheat and apple contain detectable amount of radioactivity, which successively relocate into the human body via the ingestion pathway. We know also, that the activity of food is strictly linked to the activity of soil where food was implanted. At present, studies on health effects due to ionizing radiations have produced substantial evidences that exposure to high level of radiations can cause illness or even death. Despite a wellknown effect of cancer, scientists have long known that ionizing radiations with high doses may also cause mental retardations in the children of mothers exposed to radiations during pregnancy period [1].

Among the various implanted soils, the soil of wheat and apples has been selected to study their activity, because wheat and apples crops are very widespread. The natural radionuclides present in soil and fertilizers consist mainly of ${ }^{238} \mathrm{U},{ }^{232} \mathrm{Th}$ isotopes with their daughter products and the ${ }^{40} \mathrm{~K}[2]$.

The knowledge of activity concentrations and distributions of the radionuclides in these materials are of greater interest since it provides useful information in the monitoring of environmental radioactivity [3].

The main objective of this paper is to determine the activity concentrations of natural and artificial radionuclides in the soil samples collected from the region of Mila and to evaluate the radiological hazard. The results, may be used, as a reference data for monitoring possible radioactivity pollutions in future.

\section{Experimental procedures 2.1 Study area}

Soil samples were collected from Mila region in the northeast of Algeria. Mila province lies in the longitude of $6^{\circ} 16^{\prime} \mathrm{E}$ and in the altitude of $36^{\circ} 27^{\prime} \mathrm{N}$. It covers an area of $9375 \mathrm{~km}^{2}$ and has a population of 768419 . Mila among the best producers of cereals across the national territory.

\subsection{Samples collection and preparation}

In order to measure the natural radioactivity in the soil planted with apples and wheat, six soil samples were collected in the area referred in section 2.1. We took samples of soil planted with wheat and apples, at different depths going from 10 to $50 \mathrm{~cm}$. The distance between the sites is 100 meters, separated by breezes Winds. The materials used for soil sampling are shovel, plastic bucket, boxes, pen or marker. The soil was collected in a clean plastic bucket and mixed well. Samples of $0.5 \mathrm{~kg}$ were ground, homogenized and sieved. They were dried for 48 $\mathrm{h}$ to ensure that the moisture is completely removed. Each sample was placed in a plastic box of radius $50 \mathrm{~mm}$ and $14 \mathrm{~mm}$ thick. Before the gamma analysis was carried out, the boxes had remained hermetically sealed for four weeks, in order to establish the radioactive secular equilibrium between the radionuclides of short half-lives. This step was necessary to ensure that the radon gas remains confined within the volume and that the daughters will remain in the sample [4].

\subsection{Experimental setup}

The measurement had been carried out in the laboratory of low activities in Grenoble (LBA/LPSC) equipped with two low noise HPGe detectors. Each detector is surrounded by two $\mathrm{cm}$ of archaeological lead exempt from natural radioactivity and $15 \mathrm{~cm}$ of purified lead. The two

\footnotetext{
*Corresponding author: amina.bramki@umc.edu.dz
} 
detectors and their shielding is positioned at the center of a cube of two meters square of side surfaces, each face of the cube, with the exception of the ground, is in fact a liquid scintillation detector. These detectors act as veto prohibiting the acquisition of data during the passage of a cosmic ray. The energy calibration of the detectors was done using standard multi gamma sources. The resolution of the detectors in these measures was $0.85 \mathrm{keV}$ and 1.85 $\mathrm{keV}$ at energies $122 \mathrm{keV}$ and $1332 \mathrm{keV}$, respectively. The IAEA-RGU-1 and IAEA-RGTh-1 in powder form, installed in the same plastic box used for the samples, were used to determine the detectors efficiency curves. The activities of natural-series were $4940 \pm 30 \mathrm{~Bq} / \mathrm{kg}$ for ${ }^{238} \mathrm{U}$ and $228 \pm 2 \mathrm{~Bq} / \mathrm{kg}$ for ${ }^{235} \mathrm{U}$ in IAEA-RGU-1 and $3250 \pm 10 \mathrm{~Bq} / \mathrm{kg}$ for ${ }^{232} \mathrm{Th}$ in IAEA-RGTh-1. InterWinner software (ITECH INSTRUMENTS) was used for the acquisition and treatment of the data collected by the detectors, taking into account the dead time. Each sample placed directly over the front of the detector was measured during an accumulating time between 48 and $72 \mathrm{~h}$. The background spectrum was measured under the same conditions of samples during 1 month and was used to correct the calculated samples activities.

\section{Calculations of activity concentrations and radiological indices}

\subsection{Activity concentrations}

The activity concentrations of the radionuclides in the measured six samples (As) were computed using the following equation [5],

$$
A_{s}\left(B q \cdot \mathrm{kg}^{-1}\right)=\frac{N}{\varepsilon * I * m * t}
$$

Where $\mathrm{N}$ is the net gamma counting, $\varepsilon$ is the detector efficiency of the specific $\gamma$-ray, I is the absolute gamma intensity of gamma-decay, $\mathrm{m}$ is the masse of the sample $(\mathrm{kg})$ and $\mathrm{t}$ is the time of measurements

\subsection{Radiological Hazard Indices}

\subsubsection{Radium equivalent activity}

As seen in the introductory part of this paper, the equivalent radium activity $\left(\mathrm{Ra}_{\mathrm{eq}}\right)$ is a parameter used to estimate the external exposure due to the contribution of gamma emitters from ${ }^{226} \mathrm{Ra},{ }^{232} \mathrm{Th}$ and ${ }^{40} \mathrm{~K}$. Eq. (2) was employed for the calculation of the $\mathrm{Ra}_{\mathrm{eq}}$.

$$
R a_{e q}=A_{R a}+1.43 A_{T h}+0.077 A_{K}
$$

Where $\mathrm{A}_{\mathrm{Ra}}, \mathrm{A}_{\mathrm{Th}}$ and $\mathrm{A}_{\mathrm{K}}$ are, respectively, the radiological concentrations or specific activities obtained for ${ }^{226} \mathrm{Ra}$, ${ }^{232} \mathrm{Th}$ and ${ }^{40} \mathrm{~K}$, using Bq. $\mathrm{kg}^{-1}$ as a measurement unit [6]. The weights are based on the estimation that $370 \mathrm{~Bq} \cdot \mathrm{kg}^{-1}$ of ${ }^{226} \mathrm{Ra}, 259 \mathrm{~Bq} \cdot \mathrm{kg}^{-1}$ of ${ }^{232} \mathrm{Th}$ and $4810 \mathrm{~Bq} \cdot \mathrm{kg}^{-1}$ of ${ }^{40} \mathrm{~K}$ produce the same $\gamma$-ray dose [7].

\subsubsection{Hazard Indices $(H)$}

In order to evaluate the hazard of the natural $\gamma$ radiation, the external hazard indices (Hex) was calculated from the following formula [8],

$$
H_{e x}=\frac{A_{R a}}{370 B q / K g}+\frac{A_{T h}}{259 B q / K g}+\frac{A_{K}}{4810 B q / K g}<1
$$

Where $A_{R a}, A_{T h}$, and $A_{K}$ are the activity concentrations of ${ }^{226} \mathrm{Ra},{ }^{232} \mathrm{Th}$ and ${ }^{40} \mathrm{~K}$. The Internal hazard indices $\left(\mathrm{H}_{\mathrm{in}}\right)$ is given by $\mathrm{Eq}$ (4) [9],

$$
H_{\text {in }}=\frac{A_{R a}}{185 B q / K g}+\frac{A_{T h}}{259 B q / K g}+\frac{A_{K}}{4810 B q / K g}<1
$$

\subsubsection{Representative level indice}

Another radiation hazard index called the representative level indices $\left(\mathrm{I}_{\gamma \mathrm{r}}\right)$ is defined as follows in Eq (5)

$$
I_{g r}=\frac{A_{R a}}{150 B q / K g}+\frac{A_{T h}}{100 B q / K g}+\frac{A_{K}}{1500 B q / K g}
$$

Where $A_{R a}, A_{T h}$ and $A_{K}$ are specific activities of ${ }^{226} \mathrm{Ra}$, ${ }^{232} \mathrm{Th}$ and ${ }^{40} \mathrm{~K}$ in Bq. $\mathrm{kg}^{-1}$, respectively [10].

\subsubsection{Absorbed dose rate}

The external gamma dose rate $\dot{\mathrm{D}}\left(\mathrm{nGy} \mathrm{h}^{-1}\right)$ in air at $1 \mathrm{~m}$ above the ground level caused by the presence of natural radionuclides was calculated according to the formula UNSCEAR. 2008 [11],

$$
\dot{\mathrm{D}}=0.462 C_{u}+0.604 C_{T h}+0.0417 C_{k}
$$

Where $\mathrm{C}_{\mathrm{Ra}}, \mathrm{C}_{\mathrm{Th}}$ and $\mathrm{C}_{\mathrm{K}}$ are the activity concentrations of ${ }^{226} \mathrm{Ra},{ }^{232} \mathrm{Th}$ and ${ }^{40} \mathrm{~K}\left(\mathrm{~Bq} \cdot \mathrm{kg}^{-1}\right)$.

\section{The annual effective dose equivalent and excess lifetime cancer risk}

To estimate the annual effective dose rates, the conversion coefficient from absorbed dose in air to effective dose for adults is (c=0.7 Sv/Gy) and outdoor occupancy factor $(\mathrm{p}=0.2)$ proposed by UNSCEAR were used UNSCEAR 2000 [12]. The effective dose rate in unit of $(\mu \mathrm{Sv} / \mathrm{y})$ was calculated by following equation:

$$
D_{E}=c . \dot{D} \cdot t \cdot p \cdot 10^{-3}
$$

Where $t$ is the annual exposure time $(8760 \mathrm{~h})$. Excess lifetime cancer risk outdoors (presented in table 2) was calculated as follows [13]:

$$
E L C R=D_{E} \cdot D_{L} \cdot P C
$$

Where $\mathrm{D}_{\mathrm{E}}(\mu \mathrm{Sv})$ is defined in $\mathrm{Eq}(7), \mathrm{D}_{\mathrm{L}}$ is the duration of life $(70 \mathrm{y})$ and $\mathrm{PC}$ is the nominal probability coefficient for detriment adjusted cancer risk of $5.5^{*} 10^{-2} \mathrm{~Sv}^{-1}$ for the whole population (ICRP. 2007). 


\section{Results and discussion}

\subsection{THE ACTIVITY CONCENTRATIONS}

The results of activity concentrations in the soil samples from the six different sites are gives in table 1 for the natural radionuclides of ${ }^{226} \mathrm{Ra},{ }^{232} \mathrm{Th}$ and ${ }^{40} \mathrm{~K}$ and the artificial radionuclide ${ }^{137} \mathrm{Cs}$. Radium equivalent activity
$\left(\mathrm{Ra}_{\mathrm{eq}}\right)$, representative level indices, external hazard indices, absorbed dose rates, annual effective doses and the excess lifetime risks of cancer in soil samples are given in table 2 .

Table 1: Activity concentrations $\left(\mathrm{Bq} \cdot \mathrm{kg}^{-1}\right)$ of ${ }^{226} \mathrm{Ra},{ }^{232} \mathrm{Th},{ }^{40} \mathrm{~K}$ and ${ }^{137} \mathrm{Cs}$ for each of the measured samples

\begin{tabular}{|c|c|c|c|c|c|c|}
\hline $\mathbf{S}$ & $\mathbf{B 1 0}$ & $\mathbf{B 3 0}$ & $\mathbf{B 5 0}$ & P10 & P30 & P50 \\
\hline${ }^{40} \mathbf{K}$ & $220.80 \pm 10.01$ & $238.00 \pm 9.44$ & $248.6 \pm 12.58$ & $254.00 \pm 10.30$ & $260.70 \pm 8.24$ & $257.10 \pm 8.30$ \\
\hline${ }^{226} \mathbf{R a}$ & $23.72 \pm 2.37$ & $46.00 \pm 6.89$ & $65.47 \pm 5.06$ & $46.14 \pm 8.35$ & $55.83 \pm 5.80$ & $43.10 \pm 7.50$ \\
\hline${ }^{232} \mathbf{T h}$ & $26.60 \pm 0.88$ & $26.45 \pm 0.78$ & $27.09 \pm 1.11$ & $26.56 \pm 0.84$ & $27.10 \pm 0.80$ & $26.60 \pm 0.80$ \\
\hline${ }^{235} \mathbf{U}$ & $2.69 \pm 0.60$ & $0.90 \pm 0.38$ & $1.80 \pm 0.32$ & $1.31 \pm 0.47$ & $0.93 \pm 0.32$ & $1.44 \pm 0.40$ \\
\hline${ }^{137} \mathbf{C s}$ & $3.00 \pm 0.29$ & $2.39 \pm 0.22$ & $2.36 \pm 0.47$ & $4.10 \pm 0.27$ & $3.72 \pm 0.20$ & $3.17 \pm 0.18$ \\
\hline
\end{tabular}

Table 2. The external $\left(\mathrm{H}_{\mathrm{ex}}\right)$ and internal $\left(\mathrm{H}_{\mathrm{in}}\right)$ hazard indices, radium equivalent $\left(\mathrm{Ra}_{\mathrm{eq}}\right)$, representative level $\left(\mathrm{I}_{\gamma \mathrm{r}}\right)$, air-absorbed dose rates $(\dot{D})$, annual effective doses $\left(\mathrm{D}_{\mathrm{E}}\right)$ and excess lifetime cancer risk (ELCR) for samples.

\begin{tabular}{|c|c|c|c|c|c|c|c|}
\hline Sample name & $\begin{array}{c}\mathbf{H}_{\mathrm{ex}} \\
\left(\mathbf{B q} \cdot \mathrm{kg}^{-1}\right)\end{array}$ & $\begin{array}{c}\mathbf{H}_{\mathrm{in}} \\
\left(\mathrm{Bq} \cdot \mathrm{kg}^{-1}\right)\end{array}$ & $\begin{array}{c}\mathbf{R a}_{\mathrm{eq}} \\
\left(\mathbf{B q} \cdot \mathbf{k g}^{-1}\right)\end{array}$ & $\mathbf{I}_{\gamma \mathrm{r}}$ & $\begin{array}{c}\dot{\mathbf{D}} \\
\left(\mathrm{nGy} \cdot \mathrm{h}^{-1}\right)\end{array}$ & $\begin{array}{c}D_{E} \\
(\boldsymbol{\mu} \mathbf{S v} / \mathbf{y})\end{array}$ & $\begin{array}{c}\text { ELCR } \\
\left(10^{-4}\right)\end{array}$ \\
\hline B10 & $0.21 \pm 0.04$ & $0.28 \pm 0.05$ & $78.8 \pm 14.0$ & $0.57 \pm 0.10$ & $37.40 \pm 6.67$ & $45.87 \pm 8.18$ & $1.76 \pm 0.31$ \\
\hline B30 & $0.28 \pm 0.06$ & $0.40 \pm 0.09$ & $102.1 \pm 22.4$ & $0.73 \pm 0.16$ & $37.82 \pm 8.29$ & $46.38 \pm 10.16$ & $1.78 \pm 0.39$ \\
\hline B50 & $0.33 \pm 0.06$ & $0.51 \pm 0.09$ & $123.4 \pm 20.8$ & $0.87 \pm 0.15$ & $44.86 \pm 7.58$ & $55.02 \pm 9.29$ & $2.11 \pm 0.35$ \\
\hline P10 & $0.28 \pm 0.07$ & $0.40 \pm 0.10$ & $103.7 \pm 26.4$ & $0.74 \pm 0.19$ & $38.00 \pm 9.00$ & $46.60 \pm 11.84$ & $1.79 \pm 0.45$ \\
\hline P30 & $0.31 \pm 0.05$ & $0.46 \pm 0.08$ & $114.7 \pm 18.9$ & $0.82 \pm 0.13$ & $40.47 \pm 6.68$ & $49.63 \pm 8.19$ & $1.91 \pm 0.31$ \\
\hline P50 & $0.27 \pm 0.06$ & $0.39 \pm 0.09$ & $100.9 \pm 23.9$ & $0.72 \pm 0.17$ & $39.34 \pm 9.30$ & $48.25 \pm 11.40$ & $1.85 \pm 0.43$ \\
\hline
\end{tabular}

B10: Soil of wheat depth between 10 to $20 \mathrm{~cm}$. B30: Soil of wheat depth between 20 to $30 \mathrm{~cm}$. B50: Soil of wheat depth between 30 to $50 \mathrm{~cm}$. P10: Soil of apple depth between 10 to $20 \mathrm{~cm}$. P30: Soil of apple depth between 20 to $30 \mathrm{~cm}$. P50: Soil of apple depth between 30 to $50 \mathrm{~cm}$.

The concentrations found in the present study ranged from 23.72 \pm 2.37 (B10) to $65.47 \pm 5.06$ (B50) $\mathrm{Bq} / \mathrm{kg}$ for ${ }^{226} \mathrm{Ra}$, from $26.45 \pm 0.78(\mathrm{~B} 30)$ to $27.10 \pm 0.80(\mathrm{P} 30) \mathrm{Bq} / \mathrm{kg}$ for ${ }^{232} \mathrm{Th}$ and from $220.80 \pm 10.01$ (B10) to $260.70 \pm 8.24$ for ${ }^{40} \mathrm{~K}$.

The average activity concentrations of ${ }^{226} \mathrm{Ra},{ }^{232} \mathrm{Th}$ and ${ }^{40} \mathrm{~K}$ were found to be $46.71,26.73$ and $246.53 \mathrm{~Bq} / \mathrm{kg}$ in soil samples, respectively. The world's mean values of ${ }^{226} \mathrm{Ra},{ }^{232} \mathrm{Th}$ and ${ }^{40} \mathrm{~K}$ activity concentrations are 32,45 and $420 \mathrm{~Bq} / \mathrm{Kg}$, respectively (5). The mean value of ${ }^{226} \mathrm{Ra}$ is higher than the world's average value.

We see that only for samples cultivated with wheat, concentrations of ${ }^{40} \mathrm{~K}$ and ${ }^{226} \mathrm{Ra}$ change with depth. For all other samples, the concentration of radionuclides does not really change vertically.

For ${ }^{235} \mathrm{U}$, the average activity concentration in samples was $1.51 \pm 0.42 \mathrm{~Bq} \cdot \mathrm{kg}^{-1}$. This indicates a low presence of ${ }^{235} \mathrm{U}$ in samples because the natural abundance of ${ }^{235} \mathrm{U}$ is only $0.72 \%$ of the total uranium content [14].

The ${ }^{232} \mathrm{Th}$ activity is lower than that of ${ }^{226} \mathrm{Ra}$, whereas the ${ }^{40} \mathrm{~K}$ activity is the highest one and represents the largest contribution to the total activity of soil.

Our results show the presence of ${ }^{137} \mathrm{Cs}$ in the soil with low concentrations in all samples (mean value $=3.12$ $\mathrm{Bq} \cdot \mathrm{kg}^{-1}$ ). Nuclear accidents, bomb tests and nuclear weapons are the origins of ${ }^{137} \mathrm{Cs}$ contamination. It has a half-life of about 30 years, it can be traced for several years.

The mean values of activity concentrations of ${ }^{226} \mathrm{Ra}$, ${ }^{232} \mathrm{Th}$ and ${ }^{40} \mathrm{~K}$ in soil samples from the studied area were compared with those from similar investigations in other countries such as the mean values in Jordan in 2014 are 57.7, 18.1,138.1 Bq. $\mathrm{Kg}^{-1}$ respectively [15]. They are 
however comparable to those determined in Algeria in 2011 with reported a mean values of 53.2, 50.0, 311.0 $\mathrm{Bq} . \mathrm{Kg}^{-1}$ respectively.

The resultant values from the studied area are lower than the observed from reported in Algeria in 2011 but are higher from reported in Jordan in 2014 [16].

\subsection{RADIOLOGICAL HAZARD INDICES}

Table 2 shows the calculated values of radiological effects for different samples. The calculated values of the $\mathrm{H}_{\mathrm{ex}}$ indices varied from 0.21 to 0.33 , with a mean value of 0.28 . For $\mathrm{H}_{\text {in }}$ the range was $0.28-0.51$, with a mean value of 0.41 . For all samples, $\mathrm{H}_{\text {in }}$ was less than 1

The values of calculated $\mathrm{Ra}_{\mathrm{eq}}$, for the studied samples, are shown in the fourth column of Table 2 . The calculated $\mathrm{Ra}_{\mathrm{eq}}$ values range from 78.8 (B10) to 123.4 (B50) $\mathrm{Bq} \cdot \mathrm{kg}^{-1}$. All the values of $\mathrm{Ra}_{\mathrm{eq}}$ in the studied samples are lower than the critical limit of $370 \mathrm{~Bq} \cdot \mathrm{kg}^{-1}$ [10].

The representative level indices $I_{\gamma \mathrm{r}}$ for all samples under study was smaller than unity. The calculated effective doses for the samples are under the worldwide value $80 \mu \mathrm{Sv} / \mathrm{y}$.

Finally, the excess lifetime cancer risk (ELCR) in the samples is ranged from $1.76 \times 10^{-4}$ in $\mathrm{B} 10$ to $2.11 \times 10^{-4}$ in B50 for adults. The samples are under the worldwide average of $2.54 \times 10^{-4}$ (taking into account the average annual effective dose of $66 \mu \mathrm{Sv}$ from [11].

\section{Conclusion}

Activity concentrations of ${ }^{226} \mathrm{Ra},{ }^{235} \mathrm{U},{ }^{232} \mathrm{Th},{ }^{40} \mathrm{~K}$ and ${ }^{137} \mathrm{Cs}$ were determined by using gamma-ray spectroscopy for soil samples at different depths from the El Athmania agricultural region of Mila in Algeria. The results show the presence of a low concentration of ${ }^{137} \mathrm{Cs}$ in soil, with a mean value of $3.12 \mathrm{~Bq} \cdot \mathrm{kg}^{-1}$. Activity concentration of a naturally occurring radionuclide in samples were within the world average ranges which are 46.71 (10-50), 26.73 (7-50) and $246.53(100-700) \mathrm{Bq} \cdot \mathrm{kg}^{-1}$ for ${ }^{226} \mathrm{Ra},{ }^{232} \mathrm{Th}$ and ${ }^{40} \mathrm{~K}$ respectively [12].
The value of $\mathrm{Ra}_{\mathrm{eq}}$ activity concentrations for soil samples is less than $370 \mathrm{~Bq} \mathrm{~kg}$. The average annual effective dosages are also lower than the global average values. ELCR varies from $1.76 \times 10^{-4}$ to $2.11 \times 10^{-4}$ with mean value of $1.87 \times 10^{-4}$. This study established a map of baseline information for future studies on radiation levels and radionuclide distribution in the environment of Mila. The results of the study serve as a reference for future assessment.

\section{References}

1. M. Rafik, S. Ur Rahman, M. Basharat c, W. Aziz, I. Ahmad, K. A. Lone, K.Ahmad and Matiullah, J. Radiat. Res. Appl. Sci. 7, 29 (2014).

2. N.K. Ahmed, A.G.M. El-Arabi, J. Environ. Radioact. 84, 51 (2005).

3. O. Agar, I. Boztosun, M. E. Korkmaz, S. F. Özmen, Rad. Prot. Dosimet. 162, 630 (2014).

4. Oktay Baykara, Mahmut Doğru, Radiat. Meas. 41, 362 (2005).

5. Ch. Lakehal, M. Ramdhane, A. Boucenna, J. Environ. Radioact. 101, 377 (2010).

6. J.A . Santos Júnior, R.S. Amaral, C.M. Silva, R.S.C. Menezes, Radiat. Meas. 45, 861 (2010).

7. I.P. Farai, J.A. Ademola, J. Environ. Radioact. 79, 119 (2005).

8. R. Ravisankar, A. Chandrasekaran, P. Vijayagopal, B. Venkatraman, G. Senthilkumar, P. Eswaran, A. Rajalakshmi, Radiat. Phys. Chem. 81, 1789 (2012).

9. B.A. Almayahi, A.A. Tajuddin, M.S. Jaafar, Appli. Radia. Isotop. 70, 2652 (2012).

10. NEA-OECD, 1979. Exposure to radiation from natural radioactivity in building materaials. Report by NEA group of Experts of the nuclear energy agency, OECD, Paris, France.

11. United Nations Scientific Committee on the Exposure of the Public and Workers from Various Sources of Radiation. UNSCEAR United Nations, New York (2008).

12. United Nations Scientific Committee on the Effects of Atomic Radiation. UNSCEAR United Nations, New York (2000).

13. M. Stajic, B. Milenkovic, M. Pucarevic, N. Stojic, I. Vasiljevic, D. Nikezic, Chemosph. 146, 68 (2016).

14. A.M. El-Arabi. Radiat. Meas. 42, 94 (2007).

15. H. Saleh . M. Abu Shayeb, Ann. Nucl. Energy . 65, 184 (2014).

16. w. Boukhenfouf, A. boucenna, J. Environ. Radioact. 102, 336 (2011). 